\title{
Introducing and establishing a wide reading program in the middle years of schooling
}

\author{
Nerelie Teese
}

5 Poplar St, Echuca, Vic 3564, Australia. nteese@ brightongrammar.vic.edu.au

\begin{abstract}
This professional practice paper outlines some of the purposes of a Wide Reading Program and discusses ways in which this has been introduced to English classes in the middle years of schooling. Some of the challenges encountered in the introduction and establishment of this program are also discussed. These can include the reluctance of some readers to engage with the program and how teacher's administrative duties can prevent their full involvement in Library reading sessions. The evolution of formats used for the collection and presentation of evidence based data is also outlined.
\end{abstract}

\section{Introduction}

In 2008 this Wide Reading Program was introduced to year ten classes in a Victorian rural secondary college. Two years later it was introduced to students in the middle years of schooling at Brighton Grammar School, Melbourne, Australia. This paper details the procedures involved in introducing the wide reading program to teachers and students and discusses some of the challenges and achievements to date.

Brighton Grammar School is a boys' school in the Anglican tradition and is located in Melbourne's bay-side suburb of Brighton. Established in 1882, Brighton Grammar School is a mid-sized single campus school divided into three discrete areas: Wilson House Junior School, Rosstrevor Middle School and the Senior School. Each area has its own Library, staffed by qualified teacher librarians.

Rosstrevor Middle School caters for approximately 260 students in Years 7 and 8. I became the first qualified and experienced teacher librarian appointed to the Rosstrevor Middle School after the retirement of its long serving library technician in 2008.

\section{Definition of terms}

Middle years of schooling.

Generally this term applies to students in years five to nine. At Brighton Grammar School, the term 'middle school years' is specific to years seven and eight.

Wide reading program.

This is different from and should not be confused with Uninterrupted Sustained Silent Reading (USSR ) programs. This wide reading program is a platform or scaffold which supports regularly scheduled Library reading time in all English classes. This wide reading program neither includes nor prescribes recommended book lists. Students are encouraged to read widely by selecting books that appeal to them. Peer recommendations are a major strategy in this wide reading program.

\section{History of this wide reading program}

I first became aware of this wide reading program in the late 1990s at a School Library Association of Queensland, (SLAQ), annual conference. Ms Helen Reynolds, teacher librarian at The Southport School, presented an information session about the wide reading program she had developed and was using successfully with students at The Southport School on Queensland's Gold Coast.

Helen Reynold's presentation struck an immediate chord with me. I had recently accepted the position of Head Teacher Librarian at the Bremer State High School in Ipswich, Queensland, and was eager to develop a culture of reading throughout the school.

My previous experience as a teacher of English in other Queensland state high schools included weekly reading time for classes in every year level I taught. These reading classes were based on research indicating 
reading improved student academic performance as well as my beliefs in the benefits students receive from reading.

However, if this part of my English teaching program had ever been challenged I would not have been able to offer immediate documentation to substantiate my beliefs in the academic benefits of wide reading. Helen Reynolds' wide reading program provided academic credibility in an easy-to-read document for use by students, teachers and parents. Her wide reading program also provided a systematic structure or scaffold for regularly scheduled reading time as well as an assessment tool.

After I attended Helen Reynolds' presentation at the SLAQ conference, the Head of English at Bremer State High School and I visited Helen at The Southport School to learn more about implementing this wide reading program with year eight students.

Helen Reynolds kindly allowed us to use this wide reading program but also advised us to read and learn from the research behind her program. This was, for me, the first step in the process of introducing her wide reading program to the Bremer State High School, and has also been the most important stage of today's presentation.

More than a decade later, I knew it was time to update my knowledge of current research into the benefits of wide reading programs or wide reading at school.

Details of the reading I undertook to update my knowledge about wide reading and its benefits are provided in the References. All texts are highly recommended for their contributions to the area of wide reading as well as their readability.

\section{Introducing the wide reading program in a Victorian rural secondary college}

In 2008 I accepted the contract (temporary) position of teacher librarian at the senior campus of a Victorian country secondary college, which catered for students in years ten, eleven and twelve. I had spent most of the previous semester in a contract teaching position in English and Studies of Society and Environment, (SOSE), at this campus.

2008 was a transition year for this college as its senior campus would relocate to newer facilities at the larger junior campus at the end of the year.

In collaboration with the year ten English teachers, this wide reading program was introduced to most classes. However, after not attending several scheduled library sessions one teacher decided his class would not take part.

Two other classes began participating in the wide reading program but also withdrew after missing several scheduled library sessions. These teachers, when in the library, preferred to work on computers or mark assignments or do other administrative work instead of reading with their students.

However, two other teachers showed ongoing commitment to the wide reading program and reading with their students. I regularly presented book talks to these classes and also read with them. The teachers and I discussed our reading with each other and students. These discussions could, and did, take place anywhere at school as well as in the library.

The students in both wide reading classes showed noticeable improvement in on task behaviour when reading with their teachers. When discussing the reading lessons, teachers and I agreed that all students were reading and that over time their attitudes towards reading had improved.

Each library session followed the same procedure. On entering the library students would be given their 'Wide Reading Program Student Record Book' and move to the teaching space desks where they'd update their reading records. These booklets were kept in the Library but always accessible for students to record reading details between classes. Teachers also had access to the reading record booklets and the booklets were available for parents at parent teacher reporting evenings. 
When the wide reading program was first introduced to the classes, its purpose of establishing a regular and supported routine of reading was outlined along with some of the proven academic benefits of wide reading. This gave students two compelling reasons to actively participate: the short term goal of reading as an achievable task for assessment and reporting purposes, and the longer term goal of improved academic performance.

The first task for students on the introduction of the wide reading program was to set and record a reading goal for the first term of the school year. Students were then responsible for recording details of their progress towards meeting this goal. When this was done, students were able to begin reading, either at their desk or in the reading spaces in the library.

Regular feedback was given to each student in their record book. A positive comment was written next to the set goal and reading record details were initialled and dated. If a student commented on the book they'd finished reading, another positive comment was written close by.

English teachers received a report on each student on a fortnightly basis. Reporting to teachers was initiated at this college in response for evidence based data from library programs. Even though my temporary position at this campus had a definite finishing point, I believed the value of the wide reading program was of such worth that its data should be collected and used for the library as well as by teachers.

The report to teachers was valuable as an example of student generated data. If students were meeting their responsibilities by setting goals, regularly recording reading details and meeting or beating set goals, this was recorded. If students weren't actively participating in the program this was quickly and easily identified. The collaborative nature of the wide reading program enabled English teachers and myself to decide how we could best encourage all students, but especially reluctant readers, to become more engaged in the wide reading program.

As each wide reading class had a teacher and teacher librarian involved in the reading lesson, either of us could intervene when students weren't reading. In the early days, as we established a regular routine of reading in a school without a visible reading culture, English teachers and I would frequently refocus individuals or small groups of students. As students became more comfortable with the reading routine our intervention was needed less often.

The student reports sent to teachers were, at that stage, very basic. Initially these were presented in a word document format. With more than twenty-five students in each class these reports soon became very lengthy and by the end of the first term the report for each class was more than twenty-five pages long.

I then reformatted the reports to a chart or grid for each student where ticks were inserted in columns after each lesson. Again this was a time consuming process which also resulted in lengthy documents being emailed to teachers. Another innovation was to include a graph presentation of the data at the beginning of each report. This enabled teachers to see an overview of class performance and, if desired, refer to individual student data further in the report.

While the format of the reports was evolving the actual content or details remained the same:

- the student had set a reading goal or

- the student had not set a reading goal;

- the student was recording reading details or

- the student was not recording reading details;

- the student was borrowing library books or

- the student was not borrowing library books.

While the teachers and I regularly discussed class and individual student progress in the wide reading program, we did very little in the way of formalising our observations or the data generated through our observations and anecdotes. 
However, the feedback from parents at our first parent teacher evening was very positive as many parents from both classes commented about their children reading more at home. A mother of one student cried when she thanked the teacher for bringing her daughter back to books and reading.

At the end of the first semester, the Library statistics showed that the total borrowing from the five year ten English classes was 774 fiction and non-fiction items. This became the baseline data on which we planned to chart the progress of each English class for the rest of the year and at that stage we looked forward to the data the end of the year would bring. Unfortunately this data was never collected.

At the end of 2008 I was offered the position of teacher librarian at Rosstrevor Middle School at Brighton Grammar School in Melbourne.

\section{Introducing and establishing this wide reading program in Rosstrevor Middle School}

I started working at Rosstrevor Middle School library at the beginning of the 2009 school year. The Principal was aware of this wide reading program and asked how it could be introduced to English teachers and the existing English curriculum.

I indicated that my priority would be to develop positive relationships with all staff members, including the English faculty, and that a settling-in period would assist with the introduction of this program and other library based collaborative initiatives that would benefit students and staff.

One result of relationship building and this collaborative teaching approach saw all classes take part in a Library Online Resource and Data Base Orientation session in first term. This session focussed on the school's online resources as well as introducing a variety of search engines and their best application for school related research activities.

The school's English curriculum featured an established reading program where classes regularly came to the library for reading. In collaboration with English teachers, regular Book Talks were introduced to the reading classes. As well as promoting new and existing books, these sessions enabled students and teachers to see my passion for books and reading and also see me as a viable literary and literacy resource.

Throughout 2009 as I observed the reading classes and established myself as part of the middle school teaching team, I saw how this wide reading program would support and enhance the existing reading program.

While every English class came regularly to the library for reading, some students had developed a creative range of ways to avoid sustained engagement with reading. I felt the most obvious cause of this was that students were not accountable for their reading, or lack of reading, during library class time.

Classroom management was never an issue. The most identifiable problem seemed to be lack of student accountability. When a student finished reading a book this was expected to be recorded in his student record book. While teachers and parents were able to monitor individual reading progress through these details, it did not appear to be a systematic procedure.

Deciding how to approach teachers about the concerns I had for students who were not reading was not difficult. Complimenting teachers on the number of students actively reading established a positive rapport which then allowed concerns to be expressed about the small number of students who weren't. I found this was a shared concern and that our English teachers were keen to explore ways of encouraging reluctant readers to become more involved.

The Head of English in the middle school was interested in this wide reading program and after discussing it with the English teaching team, this program was introduced to the year seven classes at the start of the 2010 school year. The program was also trialled with some year eight classes but was not used consistently for long.

During 2010 the reports to teachers continued evolving. The lengthy word document became an individual grid report for each student per term. This allowed for checks or ticks for positive reports and crosses for negative reports in the areas outlined previously: 
- the student had set a reading goal or

- the student had not set a reading goal;

- the student was recording reading details or

- the student was not recording reading details;

- the student was borrowing library books or

- the student was not borrowing library books.

While this process was faster to produce and, I believe, easier for teachers to read, it was still time consuming and I felt it could and would be improved.

However, the purpose of the wide reading program was beginning to make itself felt as students responded to its accountability. The positive reinforcement gained from recording books after finishing them appeared to be satisfying for most students. Meeting or beating the term's set goal was also rewarding for students.

However, reluctant readers were still a concern for English teachers and myself. We would frequently discuss ways of encouraging reluctant readers to become more involved with the program. These discussions led to the inclusion of graphic novels in book talks. Many reluctant readers responded positively to this and started reading. Other reluctant readers responded well to the inclusion of 'quick reads', the small books from a variety of reading series.

2010 saw many reluctant readers engaging with books and reading, but still some teachers were not regularly participating in the wide reading program. Reasons for this were valid. If teaching or class time was lost through school related activities such as excursions, sports days, camps or other, quite often scheduled library time was relocated to class time enabling students to 'catch up' on missed teaching time. The expendability of library and reading time was understandable but frustrating. To support teachers, students and the wide reading program, when library time was cancelled, I supplied a selection of books to classrooms, enabling students to read if time allowed.

At the end of 2010, teacher relocations and staff movements saw a new Head of English appointed at the middle school. The incoming Head of English had participated in the wide reading program in 2010.

The middle years' English program was restructured to conform to the new Australian national curriculum in 2011 and the decision was made to formally include the wide reading program. This decision increased the status of the wide reading program and its original assessment tool, a formal oral book review at the end of each term, was implemented for the first time at Rosstrevor.

Towards the end of term one, all English teachers received a complete report on each student's progress in the wide reading program. This report was a combination of the data recorded in the reading record books and borrowing statistics from the library management system. English teachers used this Library information in their end of term reports, providing parents with a more detailed account of their son's reading progress.

\section{Challenges in introducing and establishing this wide reading program}

The challenges associated with introducing and establishing this wide reading program in multiple classes fall into two main categories: its routine procedures and teacher involvement.

\section{Routine procedures.}

When a student does not enter information in the record booklet, this can give a false impression that nothing is happening. If students do not leave their record booklets in the library this also interferes with the reporting process. When students do not borrow library resources for the wide reading program, this affects class statistics.

Teacher involvement.

This is by far the greatest influence on the success of the wide reading program. When a class teacher reads with his or her students in the Library, students also read. If a teacher does not read with the class, student 
reading decreases, often dramatically.

Teachers must also be involved in routine procedures. Instructions or reminders about completing reading details each lesson are more effective coming from the class teacher.

\section{Conclusion}

Introducing a wide reading program across one or more year levels can be challenging at times but is also very satisfying.

Three key learnings:

- Establishing routine procedures and teacher involvement as automatic practice will, at times, be challenging.

- Providing evidence based data is necessary in validating the program in the school community.

- The rewards for all concerned are immeasurable.

\section{References}

Atwell, N. (1998). 2nd ed. In the middle: new understandings about writing, reading, and learning. Portsmouth : Boynton/Cook Publishers.

Doiron, R \& Davies, J. (1998). Partners in learning : students, teachers and the school library. Englewood : Teacher Ideas Press.

Irvin, Judith L., Meltzer, J., Dean, N., \& Mickler, M. J. (2010). Taking the lead on adolescent literacy. Action steps for schoolwide success. Thousand Oaks : Corwin.

Jennings, P. (2008). 2nd ed. The reading bug and how to help your child catch it. Camberwell : Penguin Books.

Krashen, Stephen D. (2004). 2nd ed. The power of reading: insights from the research. Portsmouth : Libraries Unlimited.

Layne, Steven L. (2009). Igniting a passion for reading: successful strategies for building lifetime readers. Portland: Stenhouse Publishers.

Miller, D. (2009). The book whispere : awakening the inner reader in every child. San Francisco: JosseyBass.

Moloney, J. (2000) Boys and books : building a culture of reading around our boys. Sydney: ABC Books.

Nieuwenhuizen, A. (2007). Right book right time: 500 great reads for teenagers. Crows Nest: Allen \& Unwin.

Tovani, C. (2000). I read it, but I don't get it: comprehension strategies for adolescent readers. Portland: Stenhouse Publishers.

\section{Biographical Note}

Nerelie Teese is Teacher-Librarian and Teacher-In-Charge of Debating and Public Speaking at Rosstrevor Middle School, Brighton Grammar School, in Melbourne, Australia.

Ms. Teese has held the position of teacher-librarian in secondary schools and colleges in Queensland and Victoria, and has worked in the state government, Catholic, and Independent education systems. She has presented at conferences in Queensland and Canberra, ACT and was also guest speaker at school librarian meetings when she visited high school libraries during a USA study tour in 2000. Most recently she conducted a seminar called, 'Boys, Books \& Reading' for parents at Brighton Grammar School. 
